\title{
Dissecting the Salmonella response to copper
}

Correspondence

Fernando C. Soncini

soncini@ibr.gov.ar

Received 29 January 2007

Revised 8 May 2007

Accepted 15 May 2007

\author{
Martín Espariz,† Susana K. Checa,† María E. Pérez Audero, \\ Lucas B. Pontel and Fernando C. Soncini
}

\begin{abstract}
Instituto de Biología Molecular y Celular de Rosario, Consejo Nacional de Investigaciones Científicas y Técnicas, Departamento de Microbiología, Facultad de Ciencias Bioquímicas y Farmacéuticas, Universidad Nacional de Rosario, Suipacha 531, S2002LRK-Rosario, Argentina
\end{abstract}

\begin{abstract}
Intracellular copper homeostasis in bacteria is maintained as the result of a complex ensemble of cellular processes that in Escherichia coli involve the coordinated action of two systems, cue and cus. In contrast, the pathogenic bacterium Salmonella harbours only the cue regulon, including $\operatorname{cop} A$, which is shown here to be transcriptionally controlled by CueR. Mutant strains in the CueR-regulated genes were constructed to characterize the response of Salmonella enterica serovar Typhimurium to high concentrations of extracellular copper under both aerobic and anaerobic conditions. Unlike its counterpart in $E$. coli, inactivation of cuiD displays the most severe phenotype and is also required for copper tolerance under anaerobic conditions. Deletion of $\operatorname{cop} A$ has a mild effect in aerobiosis, but strongly impairs survival in the absence of oxygen. In a $\Delta \operatorname{copA}$ strain, a second Salmonella-specific P-type ATPase, GolT, can substitute the copper transporter, diminishing the effect of its deletion. The overall results highlight the importance of the cue system for controlling intracellular copper stress. The observed differences between Salmonella and $E$. coli in handling copper excess may contribute to our understanding of the distinct capability of these related pathogenic bacteria to survive outside the host.
\end{abstract}

\section{INTRODUCTION}

Copper is required in trace amounts for bacterial growth as it is an essential component of proteins required for a variety of cellular processes such as hydrolytic pathways, iron transport, respiration and defence against oxidative stress. It is also a well-known bactericide, although the mechanisms involved in copper-mediated injury have not yet been resolved (Borkow \& Gabbay, 2005; Macomber et al., 2007). In order to prevent copper damage, the cytoplasmic concentration of free copper must be negligible. The strategies used to eliminate copper excess are diverse, including different regulatory systems (MerR-like regulators, repressors and two-component systems) that modulate the expression of factors involved in active extrusion and sequestration, as well as oxidation of the metal ion in the periplasmic space (Magnani \& Solioz, 2005; Moore \& Helmann, 2005; Rensing \& Grass, 2003). Among these factors, there is a broad conservation of CPx/ P1-type ATPases, in addition to small copper-binding proteins (copper chaperones) and the sporadic presence in certain species of an RND ancillary copper-efflux system. In Escherichia coli, for instance, copper homeostasis is maintained by the coordinated action of two regulatory systems, CueR, a MerR-like protein, and the twocomponent system CusR/CusS (Outten et al., 2001;

†These authors contributed equally to this work.

Abbreviation: EMSA, electrophoretic gel mobility shift assay.
Rensing \& Grass, 2003). CueR directly stimulates the transcription of copA and cueO, coding for a P-type ATPase and a multicopper oxidase, respectively. CopA is predicted to translocate $\mathrm{Cu}(\mathrm{I})$ from the cytoplasm to the periplasmic space, where it is converted to the less toxic form $\mathrm{Cu}$ (II) by CueO (Outten et al., 2000; Petersen \& Moller, 2000; Rensing \& Grass, 2003).

The E. coli cus regulon was found to play a role in maintaining copper homeostasis under anaerobic conditions, when the oxidase $\mathrm{CueO}$ is inactive (Outten et al., 2001). The CusR/CusS system is predicted to monitor the periplasmic concentration of the metal ion, to modulate the expression of an RND-type copper efflux pump, encoded by the cusCFBA operon (Franke et al., 2003; Munson et al., 2000). Recently, it was shown that transcription of a second, uncharacterized, two-component system, encoded by the yedWV operon, is activated by copper ions in a CusR-dependent manner (Yamamoto \& Ishihama, 2005), although its role in copper tolerance remains unclear.

Other stress-response regulatory systems, such as CpxR/ CpxA and SoxR/SoxS, have been found to be induced by the addition of copper (Kershaw et al., 2005; Yamamoto \& Ishihama, 2005), probably as a result of cellular damage caused by the metal ion (Macomber, 2007)

In this work, we have characterized the Salmonella enterica serovar Typhimurium ( $S$. Typhimurium) response to 
copper. Previous reports revealed the importance of the multicopper oxidase (named CuiD in Salmonella) and the transcriptional regulator $\mathrm{CueR} / \mathrm{SctR}$ for copper tolerance (Kim et al., 2002; Lim et al., 2002). Here, we demonstrate that expression of CopA in Salmonella depends on CueR, and that this transporter and the multicopper oxidase CuiD are essential for full copper tolerance under both aerobic and anaerobic conditions. We also provide evidence that, in the absence of a functional CopA, the Salmonella-specific P-type ATPase GolT compensates for the deficiency directing active efflux of copper.

\section{METHODS}

Bacterial strains and growth conditions. Bacterial strains (all derivatives of $S$. Typhimurium 14028s) used in this study are listed in Table 1. Bacterial strains were grown overnight at $37{ }^{\circ} \mathrm{C}$ in Luria

Table 1. Bacterial strains

\begin{tabular}{|c|c|c|}
\hline Strain & Relevant genotype & Reference or source \\
\hline $14028 s$ & Wild-type & ATCC \\
\hline PB5447 & cueR:: Km & This study \\
\hline PB5449 & $\Delta c u e R$ & This study \\
\hline PB3993 & $\operatorname{cop} A:: \mathrm{Cm}$ & Checa et al. (2007) \\
\hline PB5062 & $\Delta \operatorname{cop} A$ & Checa et al. (2007) \\
\hline PB3167 & cuiD: : MudJ & Checa et al. (2007) \\
\hline PB6149 & cuiD: : MudJ $\Delta$ copA & This study \\
\hline PB3164 & gols: : Cm & Checa et al. (2007) \\
\hline PB3162 & golT: : Cm & Checa et al. (2007) \\
\hline PB3174 & golB: : Cm & Checa et al. (2007) \\
\hline PB5257 & $\Delta$ gols & Checa et al. (2007) \\
\hline PB3298 & $\Delta g o l T$ & Checa et al. (2007) \\
\hline PB3987 & $\Delta$ golTSB & Checa et al. (2007) \\
\hline PB4110 & $\Delta$ golT golB:: Cm & Checa et al. (2007) \\
\hline PB4104 & cuiD:: MudJ $\Delta$ golT & This study \\
\hline PB4107 & cuiD: : MudJ $\triangle$ golTSB & This study \\
\hline PB5826 & cuiD: : MudJ $\Delta$ golT $\Delta \operatorname{cop} A$ & This study \\
\hline PB5557 & $\Delta \operatorname{cop} A \Delta g o l T$ & This study \\
\hline PB5738 & $\Delta c o p A \Delta g o l B$ & This study \\
\hline PB5275 & $\Delta$ copA $\triangle$ golT golB: : Cm & This study \\
\hline PB5559 & $\triangle \operatorname{cop} A \triangle \operatorname{golTSB}$ & Checa et al. (2007) \\
\hline PB5737 & $\Delta c o p A \Delta g o l S$ & This study \\
\hline PB5900 & Dgols cueR:: Km & This study \\
\hline PB5430 & yedWV:: Km & This study \\
\hline PB5899 & yedWV:: Km $\Delta c u e R$ & This study \\
\hline PB5964 & yedWV $\Delta c u e R$ gols: : Cm & This study \\
\hline PB5292 & $\operatorname{cop} A:: \operatorname{lac} Z Y^{+}$ & Checa et al. (2007) \\
\hline PB5368 & $\operatorname{cop} A:: \operatorname{lac} Z Y^{+}$cueR::Km & This study \\
\hline PB5367 & $\operatorname{cop} A::{\operatorname{lac} Z Y^{+}} \Delta$ golS & This study \\
\hline PB5452 & cuiD:: MudJ $\Delta c u e R$ & This study \\
\hline PB5453 & cuiD:: MudJ $\Delta$ gols & This study \\
\hline PB3140 & golB: : lacZY $Y^{+}$ & Checa et al. (2007) \\
\hline PB5898 & golB:: ${\operatorname{lac} Z Y^{+}} \Delta c u e R$ & This study \\
\hline PB5259 & golB:: lacZY ${ }^{+}$gols & Checa et al. (2007) \\
\hline PB5143 & golB: : lac $Z Y^{+} \Delta \operatorname{cop} A$ & This study \\
\hline PB6072 & golB: : lacZY $Y^{+}$sgols $\triangle$ copA & This study \\
\hline
\end{tabular}

broth (LB) or LB-agar plates (Checa et al., 2007). Ampicillin, kanamycin and chloramphenicol were used at 100, 25 and $10 \mu \mathrm{g} \mathrm{ml}^{-1}$, respectively. When necessary, $\mathrm{CuSO}_{4}$ was added to the cultures or plates at the indicated concentration. Cell culture medium reagents and chemicals were from Sigma. Oligonucleotides were purchased from Bio-Synthesis. Primer sequences are available on request.

Genetic and molecular biology techniques. Gene disruptions or lac $Z$ reporter fusions to promoters were carried out as described previously (Datsenko \& Wanner, 2000; Ellermeier et al., 2002) in strain LB5010 (Bullas \& Ryu, 1983). All constructions were transferred to the wild-type strain 14028 s by P22 transduction (Davis et al., 1980). When necessary, the antibiotic-resistance cassette inserted at the deletion point was removed using the temperaturesensitive plasmid pCP20 carrying the FLP recombinase (Cherepanov \& Wackernagel, 1995). All mutated DNA fragments were sequenced to confirm the required mutation and to screen against undesired mutations.

The cueR locus was PCR-amplified from the Salmonella chromosome using the primers cueR-ORF-F (5'-GAGGATCCATATGAATATTAGCG-3') and cueR-ORF-R (5'-ACCCAAGCTTCAACGTGGCTTTTGC-3'). The amplified fragment was cloned into pUH21-2 laqI ${ }^{q}$ to generate the cueR-expression plasmid pCUER (pPB1205). Plasmid DNA was introduced into bacterial strains by electroporation using a Bio-Rad apparatus, following the manufacturer's recommendations.

Copper induction and inhibition assays. $\beta$-Galactosidase assays were carried out essentially as described by Miller (1972). For metalsensitivity assays, a $5 \times 10^{-7}$ dilution from overnight culture of the wild-type or each mutant strain was done in PBS. A $30 \mu \mathrm{l}$ aliquot was applied on LB plates containing increasing concentrations of $\mathrm{CuSO}_{4}$. Plates were incubated at $37{ }^{\circ} \mathrm{C}$ for $40 \mathrm{~h}$ under aerobic conditions or $64 \mathrm{~h}$ under anaerobic conditions. Anaerobic environments were generated in a Gaspak jar system using AnaeroGen sachets (Oxoid). Anaerobic indicators (Oxoid) were employed to verify oxygen consumption, following the manufacturer's recommendations. After incubation, c.f.u. per $\mathrm{ml}$ were calculated and the percentage survival was estimated based on the count of the corresponding strain grown in the absence of metal added (Checa et al., 2007).

CueR purification. Salmonella CueR was overproduced and purified from the wild-type strain carrying plasmid pCUER grown in the presence of $1 \mathrm{mM}$ IPTG essentially as described previously (Outten et al., 2000). All procedures were carried out at $4{ }^{\circ} \mathrm{C}$. The protein profile of the purified proteins was determined by SDS-PAGE. Protein concentration was determined by Bradford assay, using BSA as standard.

RNA isolation and primer extension. Total RNA was extracted from mid-exponential-phase cultures $\left(\mathrm{OD}_{600} 0.4-0.6\right)$ of wild-type $S$. Typhimurium and its isogenic $\Delta c u e R$ mutant strain grown in LB medium with or without the addition of $1 \mathrm{mM} \mathrm{CuSO}_{4}$ as previously described (Aguirre et al., 2000). cDNA synthesis was performed using 2 pmol of the ${ }^{32} \mathrm{P}$-end-labelled primer PROM-copA-R $\left(5^{\prime}\right.$ CCCAAGCTTCGCCAGCTCAACATC-3'), with $100 \mu \mathrm{g}$ total RNA and $1 \mathrm{U}$ SuperScript II $\mathrm{RNaseH} 2$ reverse transcriptase (Life Technologies). The extension products were analysed by electrophoresis on a $6 \%$ polyacrylamide- $8 \mathrm{M}$ urea gels and compared with sequence ladders initiated with the same ${ }^{32} \mathrm{P}$-labelled primer that was used for primer extension.

Protein-DNA interaction analysis. Electrophoretic gel mobility shift assays (EMSAs) were performed essentially as previously described (Lejona et al., 2003). DNA fragments (343 bp for the 
copA promoter region) were PCR-amplified using the primers PROM$\operatorname{copA-F}$ (5'-CCGGAATTCGGTGCGATAACCATT-3') and PROMcopA-R (5'-CCCAAGCTTCGCCAGCTCAACATC-3'). Labelled DNA was incubated at room temperature for $20 \mathrm{~min}$ with purified CueR in the amounts indicated in the figure. The binding buffer used for protein-DNA interactions contained $25 \mathrm{mM}$ Tris/ $\mathrm{HCl}$ ( $\mathrm{pH} 8.0$ ), $50 \mathrm{mM} \mathrm{NaCl}, 5 \mathrm{mM} \mathrm{MgCl}_{2}, 5 \mathrm{mM}$ DTT and $10 \%$ glycerol. Samples were run on an $8 \%$ non-denaturing Tris/glycine polyacrylamide gel at room temperature. After electrophoresis, the gel was dried and autoradiographed.

DNase I footprinting assay. DNase I protection assays were done for both DNA strands essentially as previously described (Aguirre et al., 2000; Lejona et al., 2003). Binding reactions with different amounts of purified CueR protein and 6 fmol labelled DNA were performed as described for the EMSAs. Then $0.05 \mathrm{U}$ DNase I (Life Technologies) was added in a final volume of $100 \mu \mathrm{l}$. After incubation for $1 \mathrm{~min}$ at room temperature, the reaction was stopped by adding $90 \mu \mathrm{l}$ of $20 \mathrm{mM}$ EDTA (pH 8), $200 \mathrm{mM} \mathrm{NaCl}$ and $100 \mu \mathrm{g} \mathrm{tRNA} \mathrm{ml}^{-1}$ . DNA fragments were purified by phenol/chloroform extraction and resuspended in $5 \mu \mathrm{H}_{2} \mathrm{O}$. Samples $(5 \mu \mathrm{l})$ were analysed by denaturing polyacrylamide $(6 \%)$ gel electrophoresis by comparison with a DNA sequence ladder generated with the appropriate primer.

\section{RESULTS}

\section{Comparative in silico analysis between $E$. coli, $S$. Typhi and S. Typhimurium copper-response regulatory networks}

We performed a BLAST search analysis in the Salmonella enterica serovar Typhimurium ( $S$. Typhimurium) and Salmonella enterica serovar Typhi ( $S$. Typhi) genomes, searching for gene product homologues to the components of the E. coli copper regulons cue and cus (Table 2). This screening revealed some important differences between these related enterobacteria. Both $S$. enterica serovars harbour orthologues to all components of the cue regulon, including the previously identified MerR-like regulator CueR/SctR, the periplasmic copper oxidase CuiD/CueO, as well as a close homologue to the inner-membrane P-type transporter CopA (Table 2). Interestingly, no orthologues to the components of the cus system were detected, except for the YedW/YedV two-component system that in E. coli was recently shown to be under transcriptional control of CusR (Yamamoto \& Ishihama, 2005). In addition, S. Typhimurium harbours a second cue-like regulon, gol. We have recently shown that this regulon, which includes a $\mathrm{P}$ type ATPase (GolT), a putative metal-binding protein (GolB) and a transcriptional regulator (GolS), endows $S$. Typhimurium with resistance to gold salts (Checa et al., 2007). The golTS operon is present in most Salmonella subspecies and in Salmonella bongori (http://www.sanger. ac.uk/Projects/Salmonella/), but absent in S. Typhi (Table 2) and S. enterica serovar Paratyphi A. On the other hand, golB is present in all sequenced salmonellas.

\section{Expression of copA in Salmonella is directly controlled by CueR}

Unlike in E. coli, in Salmonella cueR and copA are located adjacent in the genome (separated by only $110 \mathrm{nt}$ ), and transcribed divergently from each other (Fig. 1a). To probe if expression of $\operatorname{cop} A$ depends on CueR, we first constructed a strain carrying a chromosomal lac $Z$ reporter fusion to the promoter of the transporter gene (see

Table 2. E. coli copper-homeostasis genes present in S. Typhimurium and S. Typhi

\begin{tabular}{|c|c|c|c|c|c|}
\hline \multirow[t]{2}{*}{ E. coli K-12 gene } & \multirow[t]{2}{*}{ Annotation } & \multicolumn{2}{|c|}{ S. Typhimurium LT2 } & \multicolumn{2}{|c|}{ S. Typhi Ty2 } \\
\hline & & Gene & Identity $(\%)^{*}$ & Gene & Identity (\%) \\
\hline \multicolumn{6}{|l|}{ CueR regulon } \\
\hline сиеO & Multicopper oxidase & STM0168, cuiD & $(80 \%)$ & t0173, yacK & $(80 \%)$ \\
\hline copA & P-type ATPase & STM0498, copA & $(92 \%)$ & t2362, $y r b A$ & $(92 \%)$ \\
\hline cueR & MerR-type regulator & STM0499, sctR & $(91 \%)$ & $\mathrm{t} 2361$, cueR & $(91 \%)$ \\
\hline \multicolumn{6}{|l|}{ CusR regulon } \\
\hline cusR & Response regulator (TCS) & - & & - & \\
\hline cusS & Sensor kinase (TCS) & - & & - & \\
\hline cusC & Outer-membrane efflux protein & - & & - & \\
\hline cusF & Periplasmic metal resistance protein & - & & - & \\
\hline cusB & Inner-membrane efflux protein & - & & - & \\
\hline cusA & Periplasmic, RND-family efflux protein & - & & - & \\
\hline yedW & Response regulator (TCS) & STM1096, copR & $(75 \%)$ & $\mathrm{t} 1823, \operatorname{cop} R$ & $(74 \%)$ \\
\hline yed $V$ & Sensor kinase (TCS) & STM1095, copS & $(54 \%)$ & $\mathrm{t} 1824, \operatorname{cop} S$ & $(54 \%)$ \\
\hline \multicolumn{6}{|c|}{ Not present in E. coli } \\
\hline & P-type ATPase & STM0353, golT & $(42 \%$, E.c. CopA $)$ & - & \\
\hline & MerR-type regulator & STM0354, gols & $(42 \%$, E.c. CueR $)$ & - & \\
\hline & Metal chaperone & STM0355, golB & & t2511 & $\begin{array}{l}(98 \%, \\
\text { STM0355) }\end{array}$ \\
\hline
\end{tabular}

${ }^{\star}$ The value represents \% of amino acid identity with the E. coli K-12 homologue protein, except when stated. 
(a)

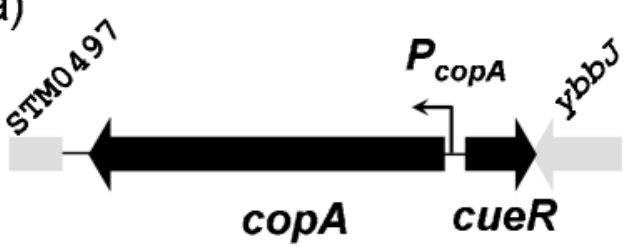

(b)

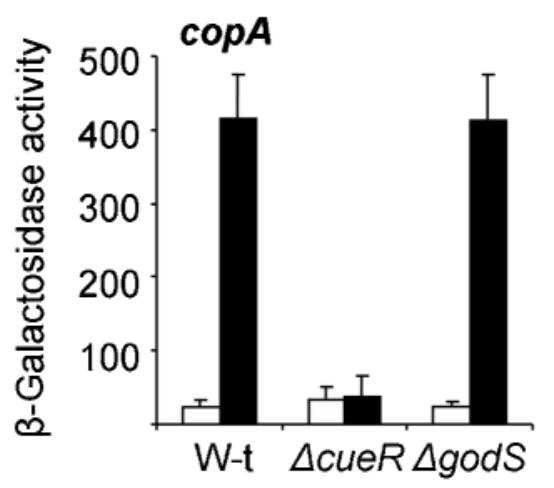

(c)

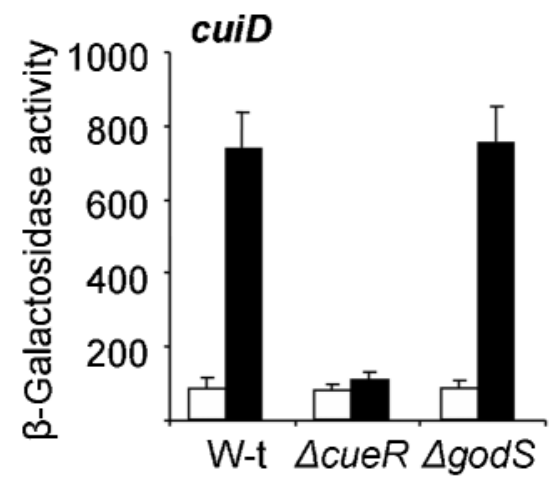

(d)

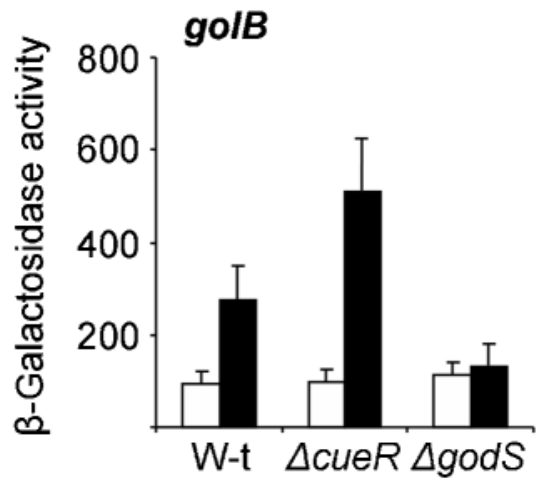

Fig. 1. Expression of $\operatorname{cop} A$ is induced by copper ions, in a CueRdependent manner. (a) Genetic organization of $\operatorname{cop} A$ and $s c t R$ genes in the $S$. Typhimurium LT2 genome. $(b-d) \beta$-Galactosidase activity (Miller units) from $\operatorname{cop} A:$ : lacZ, cuiD : : Mud J or golB : : lacZ transcriptional fusions, respectively, expressed by wild-type $(W-t)$, $\Delta c u e R$ or $\Delta g o / S$ cells after overnight growth in LB broth without (white bars), or with the addition of $1 \mathrm{mM} \mathrm{CuSO}_{4}$ (black bars). The data correspond to means \pm SD of three independent experiments done in duplicate.
Methods for details) and assayed its expression in the presence or absence of copper ions. The lac $Z$ insertion was generated as a $\operatorname{cop} A$ operon fusion, without disrupting the transporter gene. This will ensure proper copper efflux. Addition of $1 \mathrm{mM} \mathrm{CuSO}_{4}$ to the culture medium induced copA expression by 13-fold in LB (Fig. 1b) and by eightfold in SM9 minimal medium (Checa et al., 2007). This copperdependent activation of $\operatorname{cop} A$ was eliminated in a cueR null mutant, but not affected in a $\Delta$ golS strain, confirming that CueR controls the expression of the $\mathrm{Cu}(\mathrm{I})$ transporter CopA in Salmonella. A similar result was obtained using a cuiD-lacZ reporter whose expression also depends on CueR (Fig. 1c). Interestingly, deletion of $c u e R$ increased rather than decreased copper-induced expression of the GolScontrolled gene golB (Fig. 1d). This increase probably reflects accumulation of cytoplasmic copper ions, because of low-level expression of CopA in the $\triangle c u e R$ strain (Fig. 1b, see also below).

To confirm that $\operatorname{cop} A$ transcription in Salmonella is controlled directly by the transcriptional regulator CueR, we first mapped the transcription start site of the gene by primer extension analysis, using RNA isolated from wildtype or $\Delta c u e R$ mutant cells grown in the presence or absence of $\mathrm{CuSO}_{4}$. A single primer extension product, corresponding to a $\mathrm{G}$ residue located $26 \mathrm{nt}$ upstream of the $\operatorname{cop} A$ start codon, was observed only in samples obtained from the wild-type strain grown in the presence of copper ions (Fig. 2a). The Salmonella $\operatorname{cop} A$ transcription start site differs in one base from the one determined previously in E. coli by Outten et al., (2000), Petersen \& Moller (2000) and Stoyanov et al. (2001).

We performed EMSA and DNase I footprinting using purified Salmonella CueR to confirm direct binding (Fig. 2b, c). Both the extension of the protected region (from nt -39 to -13 relative to the transcription start site in the coding strand and from nt -15 to -40 in the noncoding strand) and the presence of hypersensitive bands (at nt -31 and -19 and at -33 and -21 in the coding and non-coding strands, respectively) are common features of the protein-DNA interaction described for the MerR family (Ansari et al., 1995; O’Halloran et al., 1989; Outten et al., 1999). The protected sequence of the $\operatorname{cop} A$ promoter encompasses the sequence 5'-TTGACCTTAACCTTGCTGGAAGGTTTA-3', which includes an imperfect ACCTTCC inverted repeat sequence located between the predicted -35 and -10 elements in the $\operatorname{cop} A$ promoter region, is similar to the predicted $E$. coli CueR-binding site (Fig. 2c, d; Outten et al., 2000; Stoyanov et al., 2001; Yamamoto \& Ishihama, 2005).

\section{CopA and CuiD are essential for copper tolerance under both aerobic and anaerobic conditions}

We performed copper-sensitivity assays under both aerobic and anaerobic conditions using different mutant strains in the CueR-regulated genes. In the presence of oxygen, copper tolerance decreased in strains carrying mutations in 
(a)

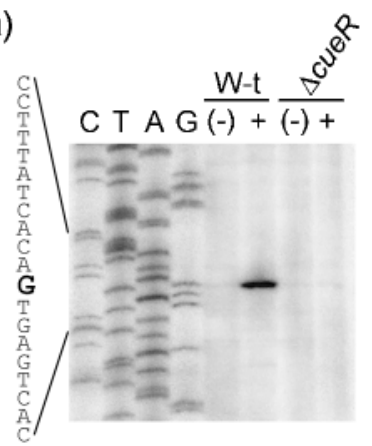

(c)
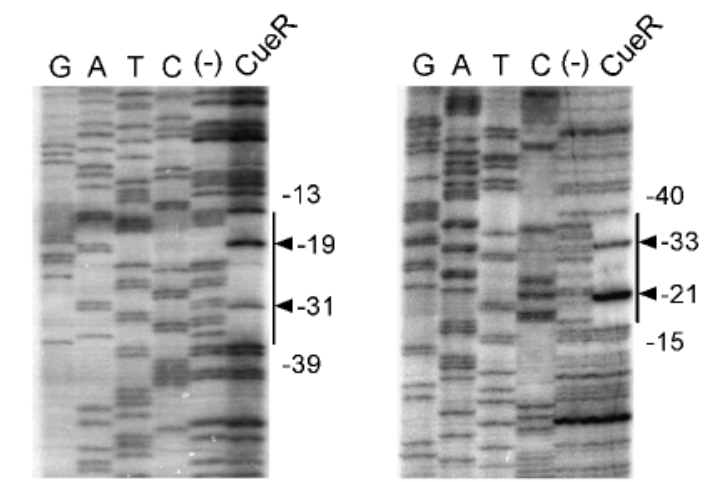

coding strand

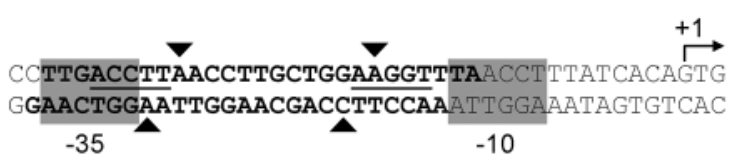

(d)

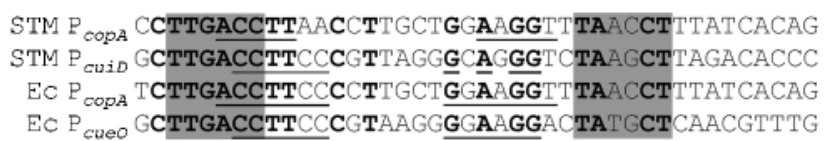

Fig. 2. CueR binds to the promoter region of $\operatorname{cop} A$. (a) Primer extension analysis of $\operatorname{cop} A$ using RNA isolated from midexponential-phase wild-type or $\Delta$ cueR cells grown in LB with or without the addition of $1 \mathrm{mM} \mathrm{CuSO}_{4}$. The sequence spanning the transcription start site (bold) is shown. (b) EMSA was performed using the ${ }^{32} \mathrm{P} 3^{\prime}$-end-labelled PCR fragment of the promoter region of $\operatorname{copA}$ incubated with purified CueR at final concentrations of $0,0.2,0.4,0.8,1.6$ and $3.2 \mu \mathrm{M}$. (c) DNA footprinting analysis of the promoter region of $\operatorname{cop} A$ was performed on both end-labelled coding and non-coding strands. Purified CueR protein $(C u e R, 6 \mu \mathrm{M})$ was added to the DNA fragments. Solid lines and arrows indicate the CueR-protected region and hypersensitive sites, respectively. The sequence at the bottom shows the copA promoter region. The CueR-protected region is indicated in boldface, and the inverted repeat CueR box is underlined. The DNase-hypersensitive sites are indicated by arrows. The transcription start site as well as the -10 and -35 elements (grey boxes) are also indicated. (d) Alignment of the promoter regions of copA and cueO homologues from $S$. Typhimurium and $E$. coli showing the predicted -35 and -10 regions (grey boxes), and the putative CueR operator (underlined). either cueR, copA or cuiD, although the latter strain showed the most severe phenotype (Table 3 ). Copper susceptibility increased even more in the cuiD copA double mutant strain, supporting the relevant role of both proteins in maintaining copper homeostasis. The marked copper susceptibility of the single cuiD mutant compared with the $\triangle c u e R$ or the $\triangle c o p A$ strains suggests that even basal levels of CuiD are enough to guarantee survival in copperrich medium, and supports the crucial role assigned to this enzyme for copper tolerance under aerobic conditions in Salmonella (Lim et al., 2002).

The role of CopA in copper tolerance acquired more relevance in the absence of oxygen (Table 3), when the multicopper oxidase $\mathrm{CueO}$ is predicted to be inactive (Outten et al., 2001). Unexpectedly, we observed that survival of a cuiD mutant strain in the presence of copper was affected even in cells grown under anaerobic conditions (Table 3), suggesting that the encoded enzyme could play an additional role in copper homeostasis in Salmonella. Periplasmic multicopper oxidases are involved

Table 3. Copper tolerance phenotype of the $S$. Typhimurium mutant strains analysed in this work

\begin{tabular}{|c|c|c|}
\hline \multirow[t]{2}{*}{ Strain } & \multicolumn{2}{|c|}{$\operatorname{MIC}(\mathbf{m M})^{\star}$} \\
\hline & $+\mathrm{O}_{2}$ & $-\mathrm{O}_{2}$ \\
\hline \multicolumn{3}{|l|}{ CueR regulon } \\
\hline Wild-type & 5.50 & 0.70 \\
\hline cueR & 4.50 & 0.45 \\
\hline cuiD & 1.25 & 0.50 \\
\hline $\operatorname{cop} A$ & 4.50 & 0.45 \\
\hline cuiD copA & 1.00 & ND \\
\hline \multicolumn{3}{|l|}{ YedW/V system } \\
\hline yedWV & 5.50 & 0.70 \\
\hline cueR yedWV & 4.50 & 0.45 \\
\hline cueR gols yedWV & $4.50 \dagger$ & 0.45 \\
\hline \multicolumn{3}{|l|}{ GolS regulon } \\
\hline gols & 5.50 & 0.70 \\
\hline golT & 5.50 & ND \\
\hline golTSB & 5.50 & 0.70 \\
\hline cuiD golT & 1.25 & ND \\
\hline cuiD golTSB & 1.25 & $\mathrm{ND}$ \\
\hline cuiD copA golT & 0.75 & 0.23 \\
\hline copA golT & 2.75 & ND \\
\hline copA golB & 4.50 & $\mathrm{ND}$ \\
\hline copA golTB & 2.50 & $\mathrm{ND}$ \\
\hline copA golTSB & 2.50 & 0.23 \\
\hline copA gols & 3.00 & $\mathrm{ND}$ \\
\hline cueR gols & $4.50 \dagger$ & 0.45 \\
\hline
\end{tabular}

${ }^{*}$ MIC values were determined on LB plates containing increasing amounts of $\mathrm{CuSO}_{4}$ under both aerobic $\left(+\mathrm{O}_{2}\right)$ and anaerobic $\left(-\mathrm{O}_{2}\right)$ conditions (see Methods for details). The data correspond to mean values of three independent experiments done in triplicate; ND, not determined.

$\dagger$ Smaller colonies were observed compared with the single cueR mutant or with the $\Delta c u e R \Delta y e d W V$ strain. 
in the conversion of the harmful $\mathrm{Cu}$ (I) to $\mathrm{Cu}$ (II) in the presence of oxygen (Singh et al., 2004; Tree et al., 2005).

We observed that under anaerobic conditions copper inhibited the bacterial growth even more strongly than under aerobic conditions (Table 3), as was previously observed in E. coli (Beswick et al., 1976; Outten et al., 2001; Rensing \& Grass, 2003). This supports the notion that copper injury to bacterial cells cannot be mediated exclusively by oxidative DNA damage (Macomber et al., 2007).

\section{The Salmonella YedW/YedV system is not involved in copper homeostasis}

Salmonella lacks the ancillary copper-detoxification cus system, but conserves genes homologous to the E. coli yedWV operon, STM1096 and STM1095 (Table 1). The yed $W V$ operon encodes a two-component system, transcription of which in E. coli is activated by copper ions (Yamamoto \& Ishihama, 2005).

We analysed whether YedW/YedV contributed to maintaining copper homeostasis in Salmonella, testing survival of the $\Delta y e d W V$ mutant strain in the presence of $\mathrm{CuSO}_{4}$ (Table 3). yed $W V$ expression is not induced by addition of up to $2 \mathrm{mM} \mathrm{CuSO}_{4}$ (data not shown). Moreover, deletion of yed $W V$ does not affect copper tolerance of the wild-type strain or of the $\Delta c u e R$ or the $\Delta c u e R \Delta$ golS mutants (see below), under either aerobic or anaerobic conditions, arguing against a role of this operon in copper homeostasis in Salmonella.

\section{The gold transporter GolT can contribute to copper tolerance in the absence of CopA}

We have recently shown that Salmonella has a second CueR homologue highly sensitive to gold ions, GolS, which induces the expression of a CopA-homologous protein, GolT, and a putative metal-binding protein, GolB (Checa et al., 2007). We found that this Salmonella-specific regulon is required for gold resistance, but not for copper tolerance, except in a strain in which the main copper transporter CopA has been deleted (Checa et al., 2007; see also Table 3). These results prompted us to investigate whether some of the GolS-controlled genes, including golS, would acquire relevance in copper homeostasis when the ancestral copper-detoxification system cue is inactive or absent. We constructed a series of mutant strains in which $\operatorname{cop} A$ and the different genes coding for components of the gol regulon were deleted. As seen in Table 3, only the deletion of the P-type metal transporter gene golT rendered a marked reduction in copper tolerance in a $\Delta \operatorname{cop} A$ strain. Moreover, the simultaneous deletion of the two transporter genes, copA and golT, further increased the susceptibility of a copA cuiD mutant strain. The contribution of GolT to copper detoxification in the absence of a functional CopA was also observed in cells grown under anaerobic conditions (Table 3). Unlike golT, deletion of golB did not affect metal tolerance of a $\Delta \operatorname{cop} A$ strain, but slightly reduced survival of a strain with both CopA and GolT transporters deleted (Table 3). Neither single mutants in GolS-regulated genes, nor a mutant with the whole gol locus deleted, altered Salmonella copper susceptibility of a cuiD or a wild-type background (Table 3 ). In accordance, deletion of the gold-sensor gene gols had only a minor effect on copper tolerance in a $\Delta c u e R$ mutant strain (Table 3), which was only evident in liquid media and under aerobic conditions (Fig. 3a).

From the above results, we asked how proper GolT levels could be acquired in a $\operatorname{cop} A$ mutant to cope with toxic copper levels, its expression being controlled by GolS, which is a poor copper sensor (Checa et al., 2007). We analysed the copper-induced expression of golB as a GolSdependent gene, in wild-type and $\triangle \operatorname{cop} A$ backgrounds (Fig. 3b). Copper-induced golB expression increased up to 24 -fold in the $\triangle \operatorname{cop} A$ strain compared with the levels obtained in the wild-type strain. This induction was dependent on the intactness of gols (Fig. 3b), suggesting that, in the absence of CopA, there is a rise of intracellular copper concentration that can induce the expression of the gol regulon. In this condition, GolT will contribute to transporting the excess copper ions out of the cytoplasm, reducing the toxicity of the cation. In support of these observations, we found an increase in copper susceptibility of the double $\Delta c o p A \Delta g o l S$ mutant when compared with the single mutants (Table 3; see also Fig. 3c). Altogether, these results indicate that, in the absence of the main copper transporter, at least some of the factors controlled by GolS can assist in copper tolerance.

\section{DISCUSSION}

Copper homeostasis in bacteria is guaranteed mainly by the action of active efflux systems that remove the metal ion from the cell (Magnani \& Solioz, 2005; Moore \& Helmann, 2005; Nies, 2003; Rensing \& Grass, 2003). Among these systems, transporters of the P-type ATPases family (Arguello et al., 2007; Kuhlbrandt, 2004) are usually involved. We have demonstrated here that expression of the Salmonella P-type ATPase CopA is induced by copper ions in a CueR-dependent manner (Figs 1 and 2) and that deletion of the copA gene affects copper tolerance under both aerobic and anaerobic conditions (Table 3 ). These observations, in addition to the previously reported role of CueR and CuiD in copper homeostasis (Kim et al., 2002; Lim et al., 2002), indicate that this pathogenic enterobacterium possesses a complete and functional cue system, similar to the E. coli counterpart (Outten et al., 2000; Rensing \& Grass, 2003). Nevertheless, the contribution of CopA and CuiD to copper tolerance in Salmonella differs in some aspects from E. coli. First, the main mechanism apparently used by Salmonella to eliminate excess of copper under aerobic conditions is the conversion of $\mathrm{Cu}(\mathrm{I})$ to $\mathrm{Cu}(\mathrm{II})$ by CuiD (Table 3). Second, CuiD is also required for copper tolerance under anaerobic conditions (Table 3), 
(a)

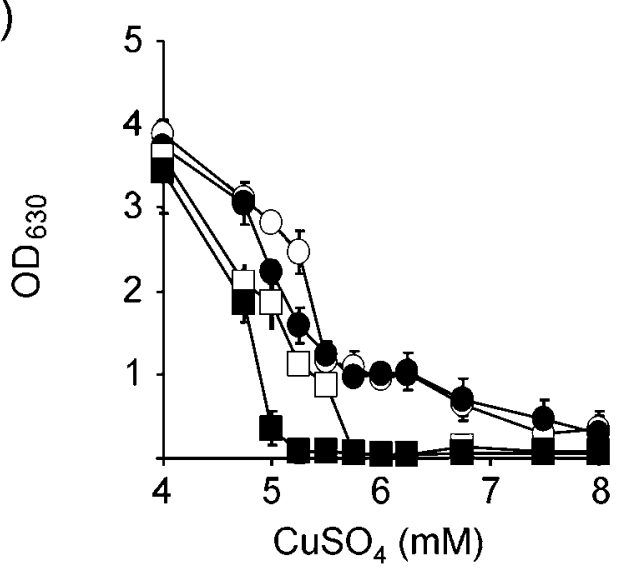

(b)

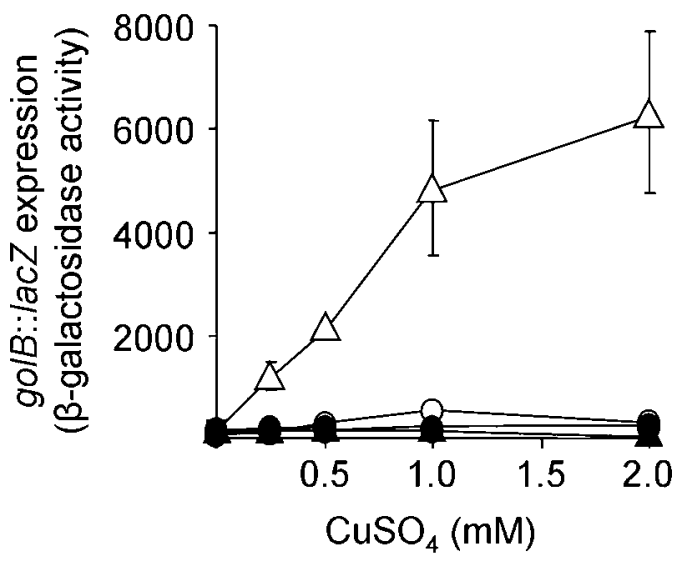

(c)

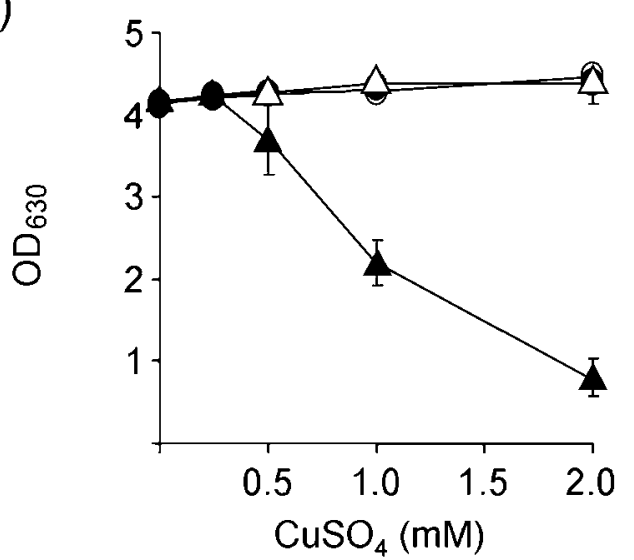

Fig. 3. GolS-controlled genes are required for copper tolerance when the cue system does not function. (a) Final $\mathrm{OD}_{630}$ reached by the cultures of wild-type $(\bigcirc), \Delta c u e R(\square), \Delta g o / S(\bullet)$ or $\Delta$ cue $R$ $\Delta g o / S$ (ם) Salmonella strains grown on LB broth containing $\mathrm{CuSO}_{4}$, at the specified concentrations. (b) $\beta$-Galactosidase activity (Miller units) from a golB::lacZ transcriptional fusion expressed by wild-type $(\bigcirc), \Delta g o / S(\bullet), \Delta \operatorname{cop} A(\triangle)$ or $\Delta g o / S$ $\triangle \operatorname{cop} A(\mathbf{\Delta})$ mutant cells, grown overnight in LB broth with or without the addition of the indicated amounts of $\mathrm{CuSO}_{4}$. (c) Final $\mathrm{OD}_{630}$ reached by the cultures used in (b). The data correspond to means \pm SD of three independent experiments done in duplicate. differing from E. coli (Outten et al., 2001). A similar effect was reported previously for the Rhodobacter capsulatus multicopper oxidase (Wiethaus et al., 2006). It has been proposed that $\mathrm{CueO}$ from E. coli can also contribute to copper tolerance by loading of the folded protein with copper ions in the cytoplasm prior to its subsequent transport into the periplasmic space by the Tat system (Rensing \& Grass, 2003). Our results suggest that this detoxification mechanism would acquire relevance in Salmonella, which lacks the ancillary cus system.

The E. coli yed $W V$ orthologous genes, although present in Salmonella (Table 2), are neither required for copper tolerance (Table 3) nor induced under excess of copper (data not shown). The above observations, in addition to the absence of E. coli cus homologues in all sequenced Salmonella serovars (Table 2 and http://www.sanger.ac.uk/ Projects/Salmonella/), highlight differences between these closely related enterobacteria in the approach used to control copper excess, in particular, in conditions where the cue system is overloaded.

In a previous report, we characterized the gol regulon that confers resistance to gold ions and demonstrated that, in the absence of the native copper transporter CopA, survival of a strain with the whole gol locus deleted is impaired in the presence of $\mathrm{CuSO}_{4}$ (Checa et al., 2007). Nevertheless, deletion of the gol locus did not affect copper tolerance of a wild-type or a $\Delta c u i D$ mutant strain. In this work, we characterized the role of the gol regulon in copper detoxification in more detail. We found that among the GolS-regulated factors, the P-type ATPase GolT is mainly responsible for alleviating copper toxicity in a $\Delta \operatorname{cop} A$ mutant strain under both aerobic and anaerobic conditions (Table 3 ), probably by directing active efflux of the metal ions from the cytoplasm. Our results suggest that in the absence of the main copper transporter CopA, the intracellular copper concentration increases, as was previously suggested to occur in E. coli (Stoyanov et al., 2003). This leads to the copper-mediated activation of GolS, enhancing the expression of its target genes (Fig. 3), including golT, which would extrude the excess of copper, mimicking the action of CopA. A number of observations indicate, however, that the contribution of the gol system to copper homeostasis in nature would be incidental and lacks physiological relevance. Copper-dependent activation of the gol regulon was only observed when the major copper transporter CopA was deleted (Fig. 3b). In addition, golT and golS are absent in S. Typhi (Table 2) and $S$. Paratyphi A. The lack of part of the gol regulon in these two serovars of $S$. enterica subspecies I, which are well-known human-adapted pathogens (Parkhill \& Thomson, 2003), supports the notion that this regulon allows Salmonella to gain access to different environmental niches. On the other hand, the two metal transporters CopA and GolT are structural and functional homologues: they share $42 \%$ identity at protein level (Table 2) and both are able to mediate either copper or gold resistance under certain conditions (Table 3; Checa et al., 2007). Therefore, it is 
highly unlikely that GolT could physiologically replace the absent cus system in Salmonella.

The periplasmic space of Gram-negative bacteria has been proposed to be an important target for copper toxicity, because two of the three copper-resistance systems from $E$. coli, $\mathrm{CueO}$ and $\mathrm{CusCFBA}$, work by removing $\mathrm{Cu}(\mathrm{I})$ from this compartment (Franke et al., 2003; Outten \& O'Halloran, 2001; Rensing \& Grass, 2003). Therefore, it will be interesting to know how Salmonella, which lacks the cus system, can avoid periplasmic copper stress under anaerobic conditions when the multicopper oxidase is inactive. The complete elucidation of the mechanisms employed by Salmonella to eliminate the excess of copper and the differences from those previously described in $E$. coli will contribute to better understanding of the distinct lifestyles of these related bacteria.

\section{ACKNOWLEDGEMENTS}

This work was supported by grants from Agencia Nacional de Promoción Científica y Tecnológica and from the National Research Council (CONICET) to F. C.S. S. K. C. is a career investigator of the CONICET, and M.E. and M.E.P.A. are fellows of the same institution. F.C.S. is a career investigator of the Rosario National University Research Council (CIUNR) and CONICET.

\section{REFERENCES}

Aguirre, A., Lejona, S., García Véscovi, E. \& Soncini, F. C. (2000). Phosphorylated PmrA interacts with the promoter region of ugd in Salmonella enterica serovar Typhimurium. J Bacteriol 182, 3874-3876.

Ansari, A. Z., Bradner, J. E. \& O'Halloran, T. V. (1995). DNA-bend modulation in a repressor-to-activator switching mechanism. Nature 374, 371-375.

Arguello, J. M., Eren, E. \& Gonzalez-Guerrero, M. (2007). The structure and function of heavy metal transport $\mathrm{P}(1 \mathrm{~B})$-ATPases. Biometals 20, 233-248.

Beswick, P. H., Hall, G. H., Hook, A. J., Little, K., McBrien, D. C. \& Lott, K. A. (1976). Copper toxicity: evidence for the conversion of cupric to cuprous copper in vivo under anaerobic conditions. Chem Biol Interact 14, 347-356.

Borkow, G. \& Gabbay, J. (2005). Copper as a biocidal tool. Curr Med Chem 12, 2163-2175.

Bullas, L. R. \& Ryu, J. I. (1983). Salmonella typhimurium LT2 strains which are $\mathrm{r}^{-} \mathrm{m}^{+}$for all three chromosomally located systems of DNA restriction and modification. J Bacteriol 156, 471-474.

Checa, S. K., Espariz, M., Pérez Audero, M. E., Botta, P. E., Spinelli, S. V. \& Soncini, F. C. (2007). Bacterial sensing of and resistance to gold salts. Mol Microbiol 63, 1307-1318.

Cherepanov, P. P. \& Wackernagel, W. (1995). Gene disruption in Escherichia coli: $\mathrm{Tc}^{\mathrm{R}}$ and $\mathrm{Km}^{\mathrm{R}}$ cassettes with the option of Flpcatalyzed excision of the antibiotic-resistance determinant. Gene 158, 9-14.

Datsenko, K. A. \& Wanner, B. L. (2000). One-step inactivation of chromosomal genes in Escherichia coli K-12 using PCR products. Proc Natl Acad Sci U S A 97, 6640-6645.

Davis, R. W., Bolstein, D. \& Roth, J. R. (1980). Advanced Bacterial Genetics. Cold Spring Harbor, NY: Cold Spring Harbor Laboratory.
Ellermeier, C. D., Janakiraman, A. \& Slauch, J. M. (2002). Construction of targeted single copy lac fusions using lambda Red and FLP-mediated site-specific recombination in bacteria. Gene 290, 153-161.

Franke, S., Grass, G., Rensing, C. \& Nies, D. H. (2003). Molecular analysis of the copper-transporting efflux system CusCFBA of Escherichia coli. J Bacteriol 185, 3804-3812.

Kershaw, C. J., Brown, N. L., Constantinidou, C., Patel, M. D. \& Hobman, J. L. (2005). The expression profile of Escherichia coli K-12 in response to minimal, optimal and excess copper concentrations. Microbiology 151, 1187-1198.

Kim, J. S., Kim, M. H., Joe, M. H., Song, S. S., Lee, I. S. \& Choi, S. Y. (2002). The sctR of Salmonella enterica serovar Typhimurium encoding a homologue of MerR protein is involved in the copperresponsive regulation of cuiD. FEMS Microbiol Lett 210, 99-103.

Kuhlbrandt, W. (2004). Biology, structure and mechanism of P-type ATPases. Nat Rev Mol Cell Biol 5, 282-295.

Lejona, S., Aguirre, A., Cabeza, M. L., García Véscovi, E. \& Soncini, F. C. (2003). Molecular characterization of the $\mathrm{Mg}^{2+}$-responsive PhoP-PhoQ regulon in Salmonella enterica. J Bacteriol 185, 6287-6294.

Lim, S. Y., Joe, M. H., Song, S. S., Lee, M. H., Foster, J. W., Park, Y. K., Choi, S. Y. \& Lee, I. S. (2002). CuiD is a crucial gene for survival at high copper environment in Salmonella enterica serovar Typhimurium. Mol Cells 14, 177-184.

Macomber, L., Rensing, C. \& Imlay, J. A. (2007). Intracellular copper does not catalyze the formation of oxidative DNA damage in Escherichia coli. J Bacteriol 189, 1616-1626.

Magnani, D. \& Solioz, M. (2005). Copper chaperone cycling and degradation in the regulation of the cop operon of Enterococcus hirae. Biometals 18, 407-412.

Miller, J. H. (1972). Experiments in Molecular Genetics. Cold Spring Harbor, NY: Cold Spring Harbor Laboratory.

Moore, C. M. \& Helmann, J. D. (2005). Metal ion homeostasis in Bacillus subtilis. Curr Opin Microbiol 8, 188-195.

Munson, G. P., Lam, D. L., Outten, F. W. \& O'Halloran, T. V. (2000). Identification of a copper-responsive two-component system on the chromosome of Escherichia coli K-12. J Bacteriol 182, 5864-5871.

Nies, D. H. (2003). Efflux-mediated heavy metal resistance in prokaryotes. FEMS Microbiol Rev 27, 313-339.

O'Halloran, T. V., Frantz, B., Shin, M. K., Ralston, D. M. \& Wright, J. G. (1989). The MerR heavy metal receptor mediates positive activation in a topologically novel transcription complex. Cell 56, 119-129.

Outten, C. E. \& O'Halloran, T. V. (2001). Femtomolar sensitivity of metalloregulatory proteins controlling zinc homeostasis. Science 292, 2488-2492.

Outten, C. E., Outten, F. W. \& O'Halloran, T. V. (1999). DNA distortion mechanism for transcriptional activation by ZntR, a Zn(II)-responsive MerR homologue in Escherichia coli. J Biol Chem 274, 37517-37524.

Outten, F. W., Outten, C. E., Hale, J. \& O'Halloran, T. V. (2000). Transcriptional activation of an Escherichia coli copper efflux regulon by the chromosomal MerR homologue, CueR. J Biol Chem 275, 31024-31029.

Outten, F. W., Huffman, D. L., Hale, J. A. \& O’Halloran, T. V. (2001). The independent cue and cus systems confer copper tolerance during aerobic and anaerobic growth in Escherichia coli. J Biol Chem 276, 30670-30677.

Parkhill, J. \& Thomson, N. (2003). Evolutionary strategies of human pathogens. Cold Spring Harb Symp Quant Biol 68, 151-158. 
Petersen, C. \& Moller, L. B. (2000). Control of copper homeostasis in Escherichia coli by a P-type ATPase, CopA, and a MerR-like transcriptional activator, CopR. Gene 261, 289-298.

Rensing, C. \& Grass, G. (2003). Escherichia coli mechanisms of copper homeostasis in a changing environment. FEMS Microbiol Rev 27, 197-213.

Singh, S. K., Grass, G., Rensing, C. \& Montfort, W. R. (2004). Cuprous oxidase activity of CueO from Escherichia coli. J Bacteriol 186, 7815-7817.

Stoyanov, J. V., Hobman, J. L. \& Brown, N. L. (2001). CueR (YbbI) of Escherichia coli is a MerR family regulator controlling expression of the copper exporter CopA. Mol Microbiol 39, 502-511.

Stoyanov, J. V., Magnani, D. \& Solioz, M. (2003). Measurement of cytoplasmic copper, silver, and gold with a lux biosensor shows copper and silver, but not gold, efflux by the CopA ATPase of Escherichia coli. FEBS Lett 546, 391-394.

Tree, J. J., Kidd, S. P., Jennings, M. P. \& McEwan, A. G. (2005). Copper sensitivity of cueO mutants of Escherichia coli K-12 and the biochemical suppression of this phenotype. Biochem Biophys Res Commun 328, 1205-1210.

Wiethaus, J., Wildner, G. F. \& Masepohl, B. (2006). The multicopper oxidase CutO confers copper tolerance to Rhodobacter capsulatus. FEMS Microbiol Lett 256, 67-74.

Yamamoto, K. \& Ishihama, A. (2005). Transcriptional response of Escherichia coli to external copper. Mol Microbiol 56, 215-227.

Edited by: J Green 